ther learned that the coming of the cattle meant food for them, hence they would meet the cattle in the shallows and follow them to deeper water. The act of these fishes leaping to secure flies from the sides of cattle is so unusual that it is deemed worthy of notice and it is hoped that the incident may be of service to those interested in animal behavior.

Roy L. Moodie.

UNIVERSITY OF Kansas.

\title{
NOTICE OF A NEW CAMEL FROM THE LOWER MIOCENE OF NEBRASKA
}

In the autumn of 1906, the writer found a nearly complete skeleton of a camel, in the Lower Harrison Beds, near Agate, Sioux County, Nebraska. The skeleton is finely preserved and articulated. It had apparently been washed into a heap while the muscles still held the bones together, for it is literally tied in knots. On this account it has only been partly removed from the matrix, and so a complete description is deferred.

The type (No. HC125, private collection of the writer) is an adult animal, and consists of a complete skull and jaws, a practically complete vertebral series, fore limbs and feet, pelvis, sacrum, and the greater portion of the hind limbs and feet. The latter were damaged by erosion. It is referred to the genus Oxydactylus, and the specific name of Campestris is proposed.

It is apparently closely related to $O$. longipes, ${ }^{1}$ but is a much smaller and somewhat less specialized type. This seems the more natural when we remember that $O$. longipes was found in a somewhat later horizon. The skull in general contour is very similar to $O$. longipes, but exhibits some distinct features. The upper incisors are proportionally slightly larger than those of 0 . longipes, the third incisor being a little larger than the canine. The diastema separating these two teeth is relatively shorter than in the latter, and the facial portion of $O$. campestris is relatively shorter. The premaxillar are separated at the proximal extremity by an unusually large U-shaped opening, $8 \mathrm{~mm}$. wide and $10 \mathrm{~mm}$. long. $P^{2}$ and $P^{3}$ are slightly more robust in the present species. The limbs are long and slender, though much shorter than those of $O$. longipes. The metacarpals are entirely separate. On the sides of the proximal end

${ }^{1}$ Annals of the Carnegie Museum, Vol. II, No. 3, pp. 434-475, 1904. 
of the metacarpals are small, flat, rugose bones, remnants of metacarpals II and V. When the specimen is entirely cleaned of the matrix, a more complete description will be given.

\section{MeAsUREMENTS}

O. campestris. 0. longipes.

Greatest length of skull.......... $290 \mathrm{~mm} . \quad 340 \mathrm{~mm}$.

Length of diastema $I^{3}$ to canine...... $7 \mathrm{~mm}$. $\quad 13 \mathrm{~mm}$.

Length of diastema canine to $P^{1} \ldots \ldots \ldots, 12 \mathrm{~mm}$. $14 \mathrm{~mm}$.

Length of diastema $P^{1}$ to $P^{2} \ldots \ldots \ldots \ldots 15 \mathrm{~mm}$. $\quad 18 \mathrm{~mm}$.

Length of continuous molar-premolar series $88 \mathrm{~mm}$. $\quad 102 \mathrm{~mm}$.

Length of metacarpals............ $275 \mathrm{~mm}$. $\quad 345 \mathrm{~mm}$.

Length of proximal phalanx........ $51 \mathrm{~mm} . \quad 66 \mathrm{~mm}$.

Length of median phalanx......... $20 \mathrm{~mm}$. $\quad 31 \mathrm{~mm}$.

Breadth of metacarpals III and V.... $15 \mathrm{~mm}$. $23 \mathrm{~mm}$.

Harold James Cook.

September 15, 1908. 